\title{
Prevalence and Related Characteristics of Carpal Tunnel Syndrome Among Orchardists in the Gyeongsangnam-do Region
}

\author{
Ho-Yeon Jung, MD, Min Sik Kong, MD, Seung Hun Lee, MD, Chang Han Lee, MD, \\ Min-Kyun Oh, MD, Eun Shin Lee, MD, Heesuk Shin, MD, Chul Ho Yoon, MD \\ Department of Rehabilitation Medicine, Gyeongsang National University Hospital, Jinju, Korea
}

\begin{abstract}
Objective To determine the prevalence and related characteristics of carpal tunnel syndrome (CTS) in orchardists and to investigate the association between electrodiagnostic severity and physical examinations.

Methods Between July 2013 and September 2014, 377 subjects ( 174 men and 203 women) visited the Gyeongsang National University Hospital's Center for Farmer's Safety and Health. All the subjects underwent electrodiagnostic tests and physical examination, including Phalen's test, Tinel's sign, and Durkan's carpal compression test (CCT). The subjects were classified into 2 groups, the normal group and the CTS group, according to electrodiagnostic test results. To determine the related characteristics of CTS, potential variables, including age, sex, drinking, smoking, body mass index, waist circumference, and total work time, were compared between the 2 groups. The association between electrodiagnostic severity and physical examinations was analyzed.

Results CTS was diagnosed in 194 subjects based only on electrodiagnostic test results, corresponding to a prevalence of $51.5 \%$. Among the variables, mean age $(\mathrm{p}=0.001)$ and total work time $(\mathrm{p}=0.007)$ were significantly correlated with CTS. With respect to the physical examinations, low specificities were observed for Tinel's sign, Phalen's test, and Durkan's CCT $(38.4 \%, 36.1 \%$, and $40.9 \%$, respectively) in the subjects aged $\geq 65$ years. In addition, Phalen's test $(\mathrm{p}=0.003)$ and Tinel's sign $(\mathrm{p}=0.032)$ in men and Durkan's CCT $(\mathrm{p}=0.047)$ in women showed statistically significant differences with increasing CTS severity. The odds ratio was 2.066 for Durkan's CCT in women according to the multivariate logistic regression analysis.

Conclusion CTS prevalence among orchardists was high, and Durkan's CCT result was significantly quantitatively correlated with the electrodiagnostic test results. Therefore, Durkan's CCT is another reliable examination method for CTS.
\end{abstract}

Keywords Carpal tunnel syndrome, Prevalence, Physical examination, Electrodiagnosis

Received February 29, 2016; Accepted April 15, 2016

Corresponding author: Chul Ho Yoon

Department of Rehabilitation Medicine, Gyeongsang National University Hospital, 79 Gangnam-ro, Jinju 52727, Korea. Tel: +82-55-750-8256, Fax: +8255-750-8255, E-mail: yoonch@gnu.ac.kr

ORCID: Ho-Yeon Jung (http://orcid.org/0000-0003-1963-2502); Min Sik Kong (http://orcid.org/0000-0003-4121-5780); Seung Hun Lee (http://orcid. org/0000-0002-3596-9458); Chang Han Lee (http://orcid.org/0000-0001-8351-5226); Min-Kyun Oh (http://orcid.org/0000-0003-0258-6298); Eun Shin Lee (http://orcid.org/0000-0002-7764-1522); Heesuk Shin (http://orcid.org/0000-0003-4181-2825); Chul Ho Yoon (http://orcid.org/0000-0003-49164180).

(a) This is an open-access article distributed under the terms of the Creative Commons Attribution Non-Commercial License (http://creativecommons.org/ licenses/by-nc/4.0) which permits unrestricted noncommercial use, distribution, and reproduction in any medium, provided the original work is properly cited. Copyright $\odot 2016$ by Korean Academy of Rehabilitation Medicine 


\section{INTRODUCTION}

Carpal tunnel syndrome (CTS) occurs due to overuse of the hand, a tumor, or external injury, and it results in narrowing of the carpal tunnel which puts pressure on the median nerve. CTS is one of the most common entrapment neuropathies of the upper limb [1-3]. In particular, it is highly related to occupations involving repeated movements and upper limb strength [4]. Accordingly, work-related CTS is a major cause of work-time restrictions and economic loss [5-7]. Previous studies reported a $0.6 \%-4.9 \%$ prevalence of CTS among typical workers $[8,9]$. However, the prevalence among agricultural workers is higher than that in office workers [10]. In Korea, the prevalence rates were $6.5 \%, 23.5 \%-26 \%, 29.4 \%$, and $16.9 \%$ among telephone exchange operators, meat-processing workers, workers in the wood-processing industry, and residents working in agricultural areas, respectively [1114]. However, despite numerous studies relating CTS to various occupations, no studies have assessed CTS among orchardists in Korea.

CTS is diagnosed based on patients' subjective signs and symptoms, physical examination results, and electrodiagnostic tests. In particular, electrodiagnostic tests have high sensitivity and specificity [15], but they are limited by the fact that they are time-consuming and need an appointment to be performed, making them difficult to implement in all patients; they also cause discomfort in patients and have high costs [16]. As a result, when physicians suspect CTS based on clinical symptoms and other physical test results, the most commonly used tests to confirm the diagnosis are Tinel's sign, Phalen's test, and Durkan's carpal compression test (CCT). Among these physical examinations, Phalen's test and Tinel's sign highly correlate with electrodiagnostic test results [17]. However, Tinel's sign and Phalen's test showed false-positive results in $25 \%$ of healthy people, and had sensitivities and specificities of $25 \%-75 \%$ and $70 \%-90 \%$, respectively, for CTS diagnosis, suggesting that physical examination findings may not always be concordant with electrodiagnostic test results $[18,19]$. No clear conclusions have been made about the relationship between electrodiagnostic test results and physical examination findings for detecting CTS, and studies on the quantitative relationships between electrodiagnostic tests and physical examinations are insufficient.
Therefore, this study investigated the prevalence of CTS in typical orchardists and identified related characteristics. The study group was expected to show a high prevalence of CTS owing to the nature of their work, which involves repeated use of the hands and wrist. Moreover, the quantitative relationships between electrodiagnostic tests and physical examination results were analyzed to assess their use in CTS diagnosis. Furthermore, the relative diagnostic values of various physical examinations were also assessed.

\section{MATERIALS AND METHODS}

\section{Study subjects}

The subjects included in this study were healthy orchardists living in Gyeongsangnam-do who participated in the health promotion program organized by the Gyeongsang National University Hospital's Center for Farmer's Safety and Health. From July 2013 to September 2014, the subjects included in this study participated in a questionnaire survey about work-related upper limb disorders, and they underwent physical examination and electromyography (EMG). Of the 414 individuals (207 men and 207 women), the subjects who received treatment for CTS, underwent surgical treatment for upper extremity trauma and fractures, or had a history of ulnar neuropathy and peripheral neuropathy due to other associated medical conditions were excluded from this study. Data obtained from 377 subjects ( 174 men and 203 women) who met the study criteria were retrospectively analyzed.

Informed consent was obtained from all the participants prior to the study, and the study was approved by the Institutional Review Board of Gyeongsang National University Hospital.

\section{Questionnaire}

The subjects completed a questionnaire about their general characteristics. The questionnaire included questions on sex, age, height, weight, waist circumference, smoking and drinking status, marital status, educational level, and total work time (see Appendix 1).

\section{Physical examinations}

Physical examinations, including Phalen's test, Tinel's sign, and Durkan's CCT, were performed to evaluate 
weakness, atrophy, and paresthesia in the abductor pollicis brevis. The aforementioned physical examinations were conducted for the hands and wrists. A positive CTS result was defined as pain and tingling sensation in some parts of the first, second, and third digits, which are supplied by the median nerve. Tinel's sign involves tapping over the median nerve at the wrist, while Phalen's test is performed by maintaining the wrists in complete flexion for 60 seconds in the direction of the palm [20]. In Durkan's CCT, the examiner applies pressure on the carpal tunnel and the underlying median nerve for 30 seconds, with the arm in supination [21].

\section{Electrodiagnostic test}

A CTS diagnosis was done based on the findings from electrodiagnostic tests, including motor and sensory nerve conduction tests for the median nerve. For the median motor nerve conduction test, a recording surface electrode was attached to the middle part of the abductor pollicis brevis before stimulating the nerve distally at the wrist and proximally at the elbow. Thereafter, the amplitude and distal latency were measured. For the median sensory nerve conduction test, the recording ring electrode was attached to the second digit before performing the antidromic stimulation technique at the $14-\mathrm{cm}$ proximal point. Subsequently, the distal latency and amplitude from the positive to the negative peak were measured. A Medelec Synergy system (Oxford Instruments, Oxford, UK) was used for the electrodiagnostic tests. In the electrodiagnostic tests, a CTS diagnosis was defined as a median motor nerve distal latency of $>4.0 \mathrm{~ms}$, a median sensory nerve distal latency of $>3.6 \mathrm{~ms}$, or a sensory nerve distal latency delay of $>0.5 \mathrm{~ms}$ as compared with those of the median and ulnar nerves in the fourth digit [22]. Median and ulnar sensory nerve latencies of $>3.6$ $\mathrm{ms}$ and $>3.7 \mathrm{~ms}$, respectively, in the electrodiagnostic tests were excluded from the analysis. The severity of CTS was classified according to Bland's classification [23] as follows: grade 0 , normal; grade 1 , CTS demonstrable only with the most sensitive test; grade 2 , delayed distal sensory nerve latency, with normal distal motor latency; grade 3 , sensory potential preserved with motor slowing, with a distal motor latency to abductor pollicis brevis of $<6.5 \mathrm{~ms}$; grade 4 , sensory potentials absent but motor response preserved, with a distal motor latency to abductor pollicis brevis of $<6.5 \mathrm{~ms}$; grade 5 , distal motor latency to abductor pollicis brevis of $>6.5 \mathrm{~ms}$; and grade 6 , sensory and motor potentials effectively unrecordable.

\section{Statistical analyses}

PASW Statistics ver. 18.0 for Windows (SPSS Inc., Chicago, IL, USA) was used for the statistical analyses. The Student t-test and Pearson $\chi^{2}$ test were used to compare the subjects' general characteristics. Cross-analysis was performed to assess the sensitivity and specificity of each of the physical examinations. The Pearson $\chi^{2}$ test, Spearman correlation analysis, and multiple regression analysis were performed to investigate the correlation between the physical examinations and CTS severity. Statistical significance was set at a $p$-value of $<0.05$.

\section{RESULTS}

\section{Prevalence of CTS}

The general characteristics of the subjects (174 men and 203 women) are presented in Table 1. CTS was diagnosed in 194 subjects based only on electrodiagnostic test results, corresponding to a prevalence of $51.5 \%$. Almost no difference in the male-to-female ratio was found between the normal and CTS groups. No statistically significant differences were found in smoking status, body mass index, and waist circumference (Table 2). However, the mean ages in the normal and CTS groups were 57.6 \pm 8.1 and $60.2 \pm 7.5$ years, respectively, indicating a statistically significant difference. Moreover, the work time until the point of testing was $28.4 \pm 13.3$ years in the normal group and 32.1 \pm 13.2 years in the CTS group, showing a statistically significant increase in total work time among orchardists with CTS (Table 2). With respect to the classification of CTS severity, $7.2 \%$ of the subjects had grade 1 CTS, $29.2 \%$ of the subjects had grade 2 CTS, $13.8 \%$ of the subjects had grade $3 \mathrm{CTS}$, none of the subjects had grade 4 CTS, $1.3 \%$ of the subjects had grade 5 CTS, and none of the subjects had grade 6 CTS, with grade 2 being the most common type (Fig. 1).

\section{Sensitivity and specificity of the physical examinations}

The sensitivity and specificity of the physical examinations are presented in Table 3. The sensitivities of Tinel's sign, Phalen's test, and Durkan's CCT were $64.9 \%, 60.0 \%$, and $59.2 \%$, respectively. The specificities of Tinel's sign, Phalen's test, and Durkan's CCT were 52.0\%, 50.5\%, and 
Table 1. Demographic characteristics of the study subjects

\begin{tabular}{|lccc}
\hline \multicolumn{1}{|c}{ Variable } & Male (n=174) & Female (n=203) & Total (n=377) \\
\hline Education & & & \\
\hline Above high school & $148(86.5)$ & $190(95.5)$ & $338(91.4)$ \\
\hline Below high school & $23(13.5)$ & $9(4.5)$ & $32(8.6)$ \\
\hline Married & $172(98.9)$ & $185(91.1)$ & $357(94.7)$ \\
\hline With spouse & $2(1.1)$ & $18(8.9)$ & $20(5.3)$ \\
\hline Single & & & \\
\hline Smoking & $57(32.8)$ & $199(98.0)$ & $256(67.9)$ \\
\hline No & $66(37.9)$ & $2(1.0)$ & $68(18.0)$ \\
\hline Past smoking behavior & $51(29.3)$ & $2(1.0)$ & $53(14.1)$ \\
\hline Present smoking behavior & & & $269(71.4)$ \\
\hline Drinking & $155(89.1)$ & $114(56.2)$ & $108(28.6)$ \\
\hline Yes & $19(10.9)$ & $89(43.8)$ & $58.9 \pm 7.9$ \\
\hline No & $60.3 \pm 8.1$ & $57.7 \pm 7.6$ & $1(0.3)$ \\
\hline Age $(\mathrm{yr})$ & $0(0.0)$ & $1(0.5)$ & $42(11.1)$ \\
\hline $30-39$ & $17(9.8)$ & $25(12.3)$ & $156(41.4)$ \\
\hline $40-49$ & $61(35.1)$ & $95(46.8)$ & $178(47.2)$ \\
\hline $50-59$ & $96(55.2)$ & $82(40.4)$ & $24.6 \pm 2.9$ \\
\hline$\geq 60$ & $24.6 \pm 2.8$ & $24.6 \pm 3.0$ & $85.6 \pm 8.3$ \\
\hline Body mass index $\left(\mathrm{kg} / \mathrm{m}^{2}\right)$ & $88.4 \pm 7.9$ & $83.3 \pm 7.9$ & $30.3 \pm 13.4$ \\
\hline Waist circumference $(\mathrm{cm})$ & $31.0 \pm 14.4$ & $29.8 \pm 12.4$ & \\
\hline Total work time $(\mathrm{yr})$ & &
\end{tabular}

Values are presented as number (\%) or mean \pm standard deviation.

Table 2. Comparison of sex, smoking, drinking, age, body mass index, waist circumference, and total work time between healthy patients and those with carpal tunnel syndrome (CTS)

\begin{tabular}{|lccc|}
\hline \multicolumn{1}{|c}{ Variable } & Normal & CTS & p-value \\
\hline Sex & & & 0.750 \\
\hline Male & $86(49.4)$ & $88(50.6)$ & \\
\hline Female & $97(47.8)$ & $106(52.2)$ & 0.386 \\
\hline Smoking & & & \\
\hline No & $119(46.5)$ & $137(53.5)$ & \\
\hline Past smoking behavior & $38(55.9)$ & $30(44.1)$ & $0.032^{*}$ \\
\hline Present smoking behavior & $26(49.1)$ & $27(50.9)$ & \\
\hline Drinking & & & \\
\hline Yes & $140(52.0)$ & $129(48.0)$ & $0.001^{*}$ \\
\hline No & $43(39.8)$ & $65(60.2)$ & 0.064 \\
\hline Age (yr) & $57.6 \pm 8.1$ & $60.2 \pm 7.5$ & 0.205 \\
\hline Body mass index $\left(\mathrm{kg} / \mathrm{m}^{2}\right)$ & $24.3 \pm 2.8$ & $24.9 \pm 2.9$ & $0.007^{*}$ \\
\hline Waist circumference $(\mathrm{cm})$ & $85.1 \pm 8.4$ & $86.2 \pm 8.1$ & $32.1 \pm 13.2$ \\
\hline Total work time $(\mathrm{yr})$ & $28.4 \pm 13.3$ & & \\
\hline
\end{tabular}

Values are presented as number (\%) or mean \pm standard deviation.

${ }^{*} \mathrm{p}<0.05$. 
$52.1 \%$, respectively. On comparing the two sexes, Phalen's test showed the highest sensitivity (70\%) in men. In addition, similar sensitivities of all examinations were observed in the individuals aged $\geq 65$ years. However, the specificities of Tinel's sign, Phalen's test, and Durkan's CCT were low at $38.4 \%, 36.1 \%$, and $40.9 \%$, respectively.

\section{Physical examination and electrodiagnostic test}

The $\chi^{2}$ test results for the severity of CTS according to the results of each physical examination are presented in Table 4. Durkan's CCT $(\mathrm{p}=0.020)$ and Tinel's sign $(\mathrm{p}=0.007)$ showed statistically significant differences with increasing CTS severity. In addition, CTS was analyzed according to sex because of the evident electrophysiological differences between men and women. Phalen's test $(\mathrm{p}=0.003)$ and Tinel's sign $(\mathrm{p}=0.032)$ in men and Durkan's CCT ( $\mathrm{p}=0.047)$ in women showed statistically significant differences with increasing CTS severity (Table 4).

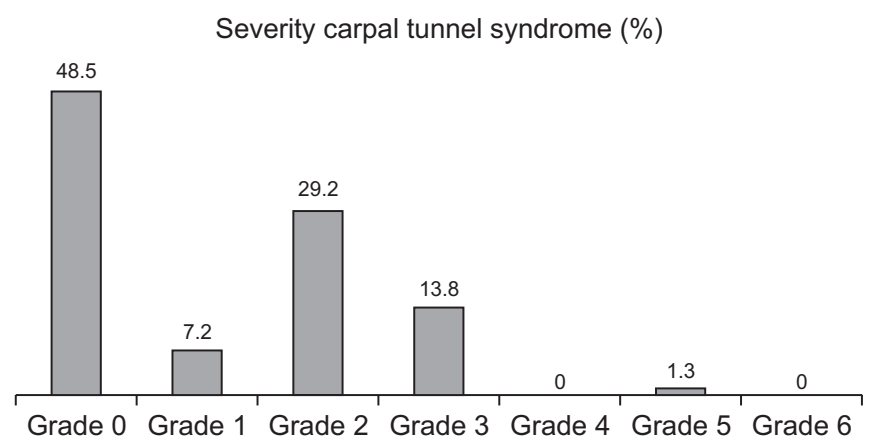

Fig. 1. Distribution of carpal tunnel syndrome severity (\%).
In the Spearman correlation analysis, Durkan's CCT and Tinel's sign each showed a statistically significant weak positive correlation, with correlation coefficients of 0.129 ( $\mathrm{p}=0.013)$ and $0.129(\mathrm{p}=0.103)$, respectively. In addition, the odds ratio was 2.066 for Durkan's CCT in women according to the multivariate logistic regression analysis, which was statistically significant. Thus, a positive finding in Durkan's CCT is a good indicator of the presence of CTS (Table 5).

The results of the physical examinations and mean latency values from the median nerve electrodiagnostic tests were analyzed and compared by using the Student

Table 3. Sensitivity and specificity of the physical examinations for diagnosis of carpal tunnel syndrome

\begin{tabular}{|c|c|c|}
\hline & Sensitivity (\%) & Specificity (\%) \\
\hline \multicolumn{3}{|l|}{ Phalen's test } \\
\hline Sex (male/female) & $70.0 / 56.0$ & $52.6 / 48.2$ \\
\hline Age $(<64 / \geq 65$ yr $)$ & $58.8 / 63.1$ & $55.0 / 36.1$ \\
\hline Total & 60.0 & 50.5 \\
\hline \multicolumn{3}{|l|}{ Durkan's CCT } \\
\hline Sex (male/female) & $61.9 / 58.1$ & $51.3 / 53.0$ \\
\hline Age $(<64 / \geq 65$ yr $)$ & $58.0 / 76.0$ & $55.6 / 40.9$ \\
\hline Total & 59.2 & 52.1 \\
\hline \multicolumn{3}{|l|}{ Tinel's sign } \\
\hline Sex (male/female) & $56.1 / 56.7$ & $52.6 / 51.4$ \\
\hline Age $(<64 / \geq 65$ yr $)$ & $53.0 / 66.6$ & $56.4 / 38.4$ \\
\hline Total & 64.9 & 52.0 \\
\hline
\end{tabular}

CCT, carpal compression test.

Table 4. Grades of electrophysiological severity and physical examinations

\begin{tabular}{|c|c|c|c|c|c|c|c|}
\hline \multirow{2}{*}{ Sex } & \multirow{2}{*}{ Grade } & \multicolumn{2}{|c|}{ Phalen's test } & \multicolumn{2}{|c|}{ Durkan's CCT } & \multicolumn{2}{|c|}{ Tinel's sign } \\
\hline & & $(+)$ & $(-)$ & $(+)$ & $(-)$ & $(+)$ & $(-)$ \\
\hline \multirow[t]{5}{*}{ Male } & 0 & 6 & 80 & 9 & 77 & 25 & 60 \\
\hline & 1 & 3 & 4 & 3 & 4 & 4 & 3 \\
\hline & 2 & 8 & 51 & 8 & 51 & 16 & 43 \\
\hline & 3 & 2 & 17 & 2 & 17 & 11 & 8 \\
\hline & 5 & 1 & 0 & 0 & 1 & 1 & 0 \\
\hline \multirow[t]{5}{*}{ Female } & 0 & 22 & 71 & 23 & 69 & 42 & 52 \\
\hline & 1 & 5 & 15 & 7 & 13 & 6 & 14 \\
\hline & 2 & 12 & 38 & 17 & 33 & 26 & 24 \\
\hline & 3 & 10 & 20 & 16 & 13 & 21 & 9 \\
\hline & 5 & 1 & 3 & 2 & 2 & 2 & 2 \\
\hline Total & & 70 & 299 & 87 & 280 & 154 & 215 \\
\hline
\end{tabular}

CCT, carpal compression test. 
Table 5. Odds ratio for carpal tunnel syndrome by multiple logistic regression

\begin{tabular}{clccc}
\hline & Sex & Odds ratio & $\mathbf{9 5 \% ~ C I ~}$ & p-value \\
\hline Phalen's test & Male & 2.593 & $0.946-7.104$ & 0.064 \\
& Female & 1.189 & $0.624-2.267$ & 0.599 \\
\hline \multirow{2}{*}{ Durkan's CCT } & Male & 1.524 & $0.614-3.778$ & 0.364 \\
\hline \multirow{2}{*}{ Tinel's sign } & Female & 2.066 & $1.118-3.817$ & $0.021^{*}$ \\
& Male & 1.422 & $0.750-2.696$ & 0.280 \\
\hline
\end{tabular}

CCT, carpal compression test; CI, confidence interval. ${ }^{*} \mathrm{p}<0.05$.

Median sensory latency (ms)

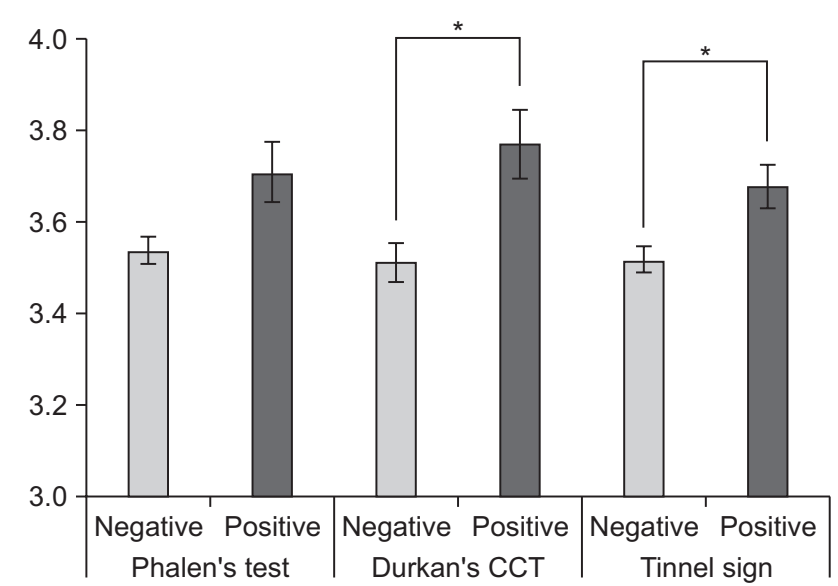

Median motor latency (ms)

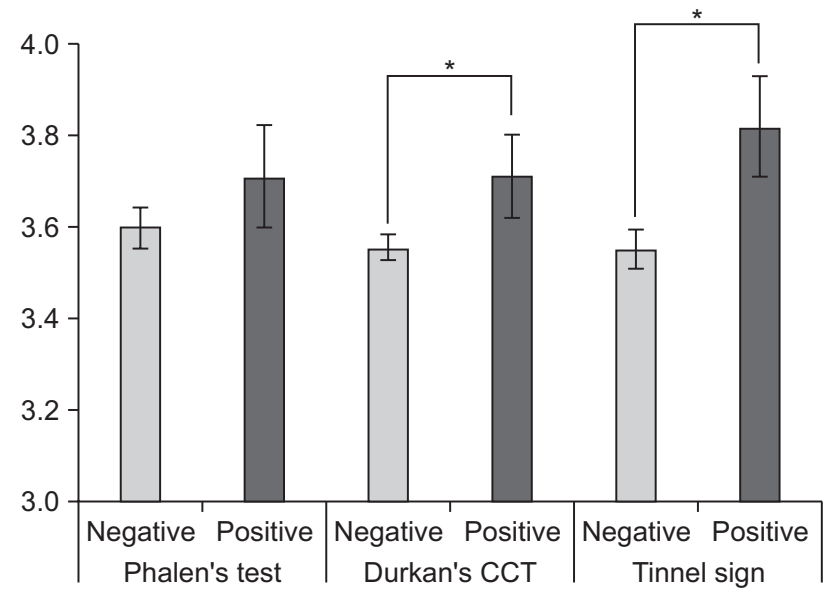

Fig. 2. Comparison of median nerve conduction latency and physical examination results (right hand). CCT, carpal compression test.

t-test (Fig. 2). The mean latency of the median sensory nerve was significantly higher in Durkan's CCT and Tinel's sign ( $\mathrm{p}=0.020$ and $\mathrm{p}=0.007$, respectively) in the CTSpositive group. The mean latency of the median motor nerve was also significantly higher in Durkan's CCT and Tinel's sign ( $\mathrm{p}=0.015$ and $\mathrm{p}=0.004$, respectively) in the CTS-positive group.

\section{DISCUSSION}

This epidemiological study revealed a higher prevalence of CTS in orchardists than in other occupational groups in the Gyeongsangnam-do region. Lee et al. [24] diagnosed CTS when patients satisfied all 6 items in the Final List of Clinical Diagnostic Criteria (2006), which was described by Graham et al. [25], and reported a CTS prevalence of $0.75 \%$ in the general Korean population. However, no specific diagnostic criteria, domestic or in- ternational, have been established for CTS in the general population.

The incidence and prevalence of CTS in typical adults are $0.125 \%-1 \%$ and $5 \%-16 \%$, respectively, and they may vary according to diagnostic criteria [4]. However, increased incidence of work-related CTS leads to a gradual increase in the prevalence. The incidence and prevalence of work-related CTS, both international and domestic, have been reported. The reported domestic prevalence rates of work-related CTS are $21.4 \%$ in rayon factory packing workers, $12.8 \%$ in condom industrial workers, $10.8 \%$ in telephone operators, and $73.9 \%$ in meat and fish processing workers. In addition, some studies reported that the CTS prevalence in farmers is $16.9 \%$ [11-14]. Based on a comparative analysis of occupational characteristics associated with CTS under surveillance from 2001 to 2004, the high-risk occupational groups for CTS included agriculture, forestry and fishery workers, simple labor work- 
ers, machine operators, and assembly workers. Among these high-risk occupational groups, agriculture-associated workers had the highest risk of developing CTS at $25.7 \%$ [26].

Compared with other occupations, orchardists use scissors with a strong grip for pruning and repeatedly flex their wrists during harvest. These repeated movements expose them to a high risk of developing CTS. In this study, $51.5 \%$ of orchardists were suspected of having CTS based on abnormal electrical diagnostic test results. Compared with other studies on high-risk workrelated CTS, this study obtained a 51.5\% CTS prevalence, which is a meaningful result that shows a relatively high prevalence. However, the differences in the prevalence rates reported by several domestic studies may be due to differences in diagnostic criteria, study design, research, regions, and population size unique to each study.

The present study only used findings from electrodiagnostic tests for the diagnosis of CTS. Therefore, selection bias might have resulted in the increased prevalence in this study, as the subjects were selected randomly from among those who participated in health screening, irrespective of the presence or absence of symptoms.

Based on previous studies that identified risk factors and characteristics related to CTS, the present study also analyzed sex, age, body mass index, waist circumference, and total work time of orchardists in the Gyeongsangnam-do region. The results showed that age and total work time significantly contributed to the development of CTS. These results support previous observations that the risk of developing CTS generally increases in middle-aged women [4]. The mean total work time until undergoing tests among orchardists in the CTS group was $32.1 \pm 13.2$ years, which was significantly longer than that in the normal group. According to the Human Development Report of the United Nations Development Programme, on a global scale, the daily work time of agricultural workers in Korea is long, and it is 10 hours 35 minutes for men and 11 hours 11 minutes for women. Thus, these long work hours of Korean agricultural workers, in addition to the year-round farming season, may support the results of the present study [27].

Although a number of physical examinations and signs have been shown to be useful for diagnosing CTS, the most well-known methods are Tinel's sign, Phalen's test, and Durkan's CCT. However, the effectiveness of these provocative tests for CTS diagnosis is controversial. These well-known physical examinations show varied results. For example, Tinel's sign has a sensitivity and specificity of $23 \%-67 \%$ and $55-100 \%$, respectively, compared with $10 \%-91 \%$ and $33 \%-100 \%$, respectively, for Phalen's test, and $28 \%-68 \%$ and $33 \%-74 \%$ for Durkan's CCT [4]. Christopher et al. [28] analyzed the literature related to CTS clinical symptoms and reported limited or no diagnostic value for Tinel's sign and Phalen's test. Conversely, Szabo et al. [29] reported high sensitivity ( $89 \%$ and $83 \%$, respectively) of Durkan's CCT and Phalen's test, and a specificity of $71 \%$ for Tinel's sign. In this study, the sensitivities of Tinel's sign, Phalen's test, and Durkan's CCT were $64.9 \%, 60.0 \%$, and $59.2 \%$, respectively, and their specificities were $52.0 \%, 50.5 \%$, and $52.1 \%$, respectively. These results show that all physical examinations performed in this study, in addition to clinical symptoms and EMG, have sufficient diagnostic value for CTS. However, in the physical examinations, low specificities were observed for Tinel's sign, Phalen's test, and Durkan's CCT (38.4\%, $36.1 \%$, and $40.9 \%$ ) in the subjects aged $\geq 65$ years. The diagnostic values of the physical examinations decreased in the elderly population. Therefore, further diagnostic tests for CTS should be performed depending on the age of the population tested.

The typical electrodiagnostic test has a reported sensitivity of approximately $77 \%$ and a false-negative rate of $10 \%-35 \%$ [30]. Although other reports indicated that electrodiagnostic testing is not useful for diagnosing CTS [31], it is generally considered essential for clinical diagnosis of CTS and is typically used in combination with several diagnostic methods to increase its sensitivity [30]. In the present study, the diagnosis and severity of CTS in orchardists from the Gyeongsangnam-do region were classified by using only the electrodiagnostic test, irrespective of the symptoms. However, the CTS severity grades suggested by Bland [23], determined by using electrodiagnostic testing, have been reported to accurately reflect clinical symptoms. As the 377 subjects had similar ages and working environments, the prevalence results of this study are highly reliable. The low sensitivity and specificity of the physical examinations in relation to the prevalence can be explained by the slight differences in the testing methods used, as the physical examinations were performed by several examiners during the course of the 1-year study. 
Opinions differ regarding the correlation between physical examination and electrodiagnostic test results in the diagnosis of CTS. Hwang et al. [32] reported a correlation of electrodiagnostic tests with Tinel's sign and Phalen's test. In contrast, Mondelli et al. [17] reported that the diagnostic values of physical tests, including Tinel's sign and Phalen's test, became limited or nonexistent as CTS severity increased. In addition, Priganc and Henry [15] investigated the correlation of CTS severity with Tinel's sign, Phalen's test, and Durkan's compression test, and they reported that the positive rate with Phalen's test increased significantly with greater severity. Jeong and Kim [33] reported that Phalen's and hand elevation tests were significantly correlated with CTS severity, with Phalen's test showing a higher correlation than the hand elevation test.

According to the results of the present study, the positive rate with the physical examinations did not increase with increased severity of CTS diagnosed by using electrodiagnostic tests. Nevertheless, the results of Tinel's sign, Durkan's CCT, and Phalen's test showed significant differences as the severity of CTS increased. Moreover, a weak but significant positive correlation was found between CTS severity and both Tinel's sign and Durkan's CCT. Of these tests, Durkan's CCT showed a significant odds ratio, which suggests that physical examination accurately reflects CTS severity. These results are not consistent with those reported by Priganc et al. [15] and Jeong and Kim [33]. However, these differences can be explained by variation in (1) study subjects, (2) study design, and (3) diagnostic criteria for CTS severity. In particular, previous studies investigated subjects with symptoms such as hand paresthesia, sensory impairment, or myasthenia, whereas the subjects in the present study consisted of orchardists with or without symptoms. This may have resulted in a low positive rate in the physical examinations and consequent discrepancies in the correlation with CTS severity.

Electrodiagnostic testing is an essential method for the diagnosis of CTS. The diagnostic characteristics include reduced conduction speed in the palm-wrist or fingerwrist segments of the median sensory nerve, and prolonged latency of the median motor nerve [34]. However, as described earlier, the present study evaluated the severity based on prolonged latency of the median sensory and motor nerves $[22,23]$. Comparison of the mean me- dian nerve latency in the electrodiagnostic tests according to the results of the 3 physical examinations revealed the median sensory and motor nerves. This suggests that out of the 3 physical examinations, Durkan's CCT best reflects the results of the electrodiagnostic test.

This study investigated the prevalence of CTS among healthy orchardists in the Gyeongsangnam-do region by analyzing clinical symptoms and EMG results. This is one of the first prevalence studies performed in domestic fruit farmers. However, this study is biased in terms of both the size and representativeness of the samples of the target population. These facts cannot be ruled out. In addition, although the prevalence reported in this study may be meaningful, the study has limitations; the value of physical examination may be relatively low because the subjects were restricted to the Gyeongsangnam-do region and the consistency in the examination is relatively inadequate because of multiple inspectors.

The CTS prevalence among orchardists from the Gyeongsangnam-do region was $51.5 \%$, which was far higher than that among the other occupational groups that use their hands and arms. Electrodiagnostic testing produced more reliable results, demonstrating a significant correlation with the results of physical examinations for CTS diagnosis. In terms of physical examinations, Durkan's CCT showed a significant quantitative correlation with the results of electrodiagnostic testing. Therefore, in addition to the well-known Tinel's sign and Phalen's test, Durkan's CCT is another reliable examination method for CTS.

\section{CONFLICT OF INTEREST}

No potential conflict of interest relevant to this article was reported.

\section{REFERENCES}

1. Dale AM, Descatha A, Coomes J, Franzblau A, Evanoff B. Physical examination has a low yield in screening for carpal tunnel syndrome. Am J Ind Med 2011;54:19.

2. de Krom MC, Knipschild PG, Kester AD, Thijs CT, Boekkooi PF, Spaans F. Carpal tunnel syndrome: prevalence in the general population. J Clin Epidemiol 1992;45:373-6. 
3. Herbert R, Gerr F, Dropkin J. Clinical evaluation and management of work-related carpal tunnel syndrome. Am J Ind Med 2000;37:62-74.

4. Aroori S, Spence RA. Carpal tunnel syndrome. Ulster Med J 2008;77:6-17.

5. Barr AE, Barbe MF, Clark BD. Work-related musculoskeletal disorders of the hand and wrist: epidemiology, pathophysiology, and sensorimotor changes. J Orthop Sports Phys Ther 2004;34:610-27.

6. Bonfiglioli R, Mattioli S, Armstrong TJ, Graziosi F, Marinelli F, Farioli A, et al. Validation of the ACGIH TLV for hand activity level in the OCTOPUS cohort: a two-year longitudinal study of carpal tunnel syndrome. Scand J Work Environ Health 2013;39:155-63.

7. Leclerc A, Franchi P, Cristofari MF, Delemotte B, Mereau P, Teyssier-Cotte C, et al. Carpal tunnel syndrome and work organisation in repetitive work: a cross sectional study in France. Study Group on Repetitive Work. Occup Environ Med 1998;55:180-7.

8. Armstrong T, Dale AM, Franzblau A, Evanoff BA. Risk factors for carpal tunnel syndrome and median neuropathy in a working population. J Occup Environ Med 2008;50:1355-64.

9. Atroshi I, Gummesson C, Johnsson R, Ornstein E, Ranstam J, Rosen I. Prevalence of carpal tunnel syndrome in a general population. JAMA 1999;282:153-8.

10. Roquelaure Y, Ha C, Pelier-Cady MC, Nicolas G, Descatha A, Leclerc A, et al. Work increases the incidence of carpal tunnel syndrome in the general population. Muscle Nerve 2008;37:477-82.

11. Lee JM, Kim SK, Kim JM. Carpal tunnel syndrome in meat-processing workers. Korean J Occup Environ Med 1999;11:407-14.

12. Sohn MK, Kim BO, Yune SH. Prevalence and diagnostic value of nerve conduction study as a screening of carpal tunnel syndrome in industry. J Korean Acad Rehabil Med 1997;21:112-20.

13. Lee J, Kwon YW, Choi JC, Choi JH, Lim HS, Kim SK. Prevalence of and risk factors for carpal tunnel syndrome in a rural population. J Korean Acad Rehabil Med 2001;25:818-26.

14. Son JE, Jang TW, Kim YK, Hong YS, Jung KY, Kim DI, et al. Survey on the prevalence of carpal tunnel syndrome in simple repetitive workers who use upper extremities. Korean J Occup Environ Med 2001;13:20919.
15. Priganc VW, Henry SM. The relationship among five common carpal tunnel syndrome tests and the severity of carpal tunnel syndrome. J Hand Ther 2003;16:225-36.

16. Ko YJ, Kim HW, Lee JI, Im S, Oh JS. The validity of the hand elevation test and its electrodiagnostic correlation for the diagnosis of carpal tunnel syndrome. J Korean EMG Electrodiagn Med 2009;11:1-6.

17. Mondelli M, Passero S, Giannini F. Provocative tests in different stages of carpal tunnel syndrome. Clin Neurol Neurosurg 2001;103:178-83.

18. Gellman H, Gelberman RH, Tan AM, Botte MJ. Carpal tunnel syndrome: an evaluation of the provocative diagnostic tests. J Bone Joint Surg Am 1986;68:735-7.

19. Golding DN, Rose DM, Selvarajah K. Clinical tests for carpal tunnel syndrome: an evaluation. Br J Rheumatol 1986;25:388-90.

20. Urbano FL. Tinel's sign and Phalen's maneuver: physical signs of carpal tunnel syndrome. Hosp Physician 2000;36:39-44.

21. Durkan JA. A new diagnostic test for carpal tunnel syndrome. J Bone Joint Surg Am 1991;73:535-8.

22. Johnson EW, Kukla RD, Wongsam PE, Piedmont A. Sensory latencies to the ring finger: normal values and relation to carpal tunnel syndrome. Arch Phys Med Rehabil 1981;62:206-8.

23. Bland JD. A neurophysiological grading scale for carpal tunnel syndrome. Muscle Nerve 2000;23:1280-3.

24. Lee JW, Kim JY, Hong YS, Kim SS, Kim WC, Kim HJ. The prevalence of carpal tunnel syndrome in an urban population. J Korean Soc Surg Hand 2008;13:26675.

25. Graham B, Regehr G, Naglie G, Wright JG. Development and validation of diagnostic criteria for carpal tunnel syndrome. J Hand Surg Am 2006;31:919-24.

26. Jung S, Chae Y, Roh S. Comparing the characteristics of cts by the frequency of exposure to wrist-burdening work: cts surveillance system, 2001-2004. Korean J Occup Environ Med 2010;22:85-94.

27. Roh S. Work-related diseases of agricultural workers in South Korea. J Korean Med Assoc 2012;55:1063-9.

28. D'Arcy CA, McGee S. The rational clinical examination: does this patient have carpal tunnel syndrome? JAMA 2000;283:3110-7.

29. Szabo RM, Slater RR Jr, Farver TB, Stanton DB, Sharman WK. The value of diagnostic testing in carpal 
tunnel syndrome. J Hand Surg Am 1999;24:704-14.

30. Lee SY, Lee SJ, Hah JS. The comparison of sensitivities of electrophysiological parameters in carpal tunnel syndrome. J Korean Neurol Assoc 2002;20:54-9.

31. Jordan R, Carter T, Cummins C. A systematic review of the utility of electrodiagnostic testing in carpal tunnel syndrome. Br J Gen Pract 2002;52:670-3.

32. Hwang MR, Kwon HK, Lee HJ. The relationship between clinical and electrodiagnostic findings in carpal tunnel syndrome. J Korean Acad Rehabil Med 1999;23:974-9.
33. Jeong DH, Kim CH. The quantitative relationship between physical examinations and the nerve conduction of the carpal tunnel syndrome in patients with and without a diabetic polyneuropathy. Ann Rehabil Med 2014;38:57-63.

34. Park KM, Shin KJ, Park J, Ha SY, Kim SE. The usefulness of terminal latency index of median nerve and f-wave difference between median and ulnar nerves in assessing the severity of carpal tunnel syndrome. J Clin Neurophysiol 2014;31:162-8. 
Ho-Yeon Jung, et al.

Appendix 1. Questionnaire about general characteristics and carpal tunnel syndrome (CTS) protocol

\section{CORD}

\section{Musculoskeletal Examination Report}

\begin{tabular}{|c|c|c|c|c|c|c|}
\hline Name & & & Sex & & Age & \\
\hline \multicolumn{7}{|l|}{ Address } \\
\hline Height & $\mathrm{cm}$ & Weight & $\mathrm{kg}$ & Phone Number & & \\
\hline Waist circumference & $\mathrm{cm}$ & Married & & Research Date & 2014/ & 1 \\
\hline Smoking & \multicolumn{6}{|c|}{$\begin{array}{l}\text { 1. No } \\
\text { 2. Ex-smokers } \\
\text { 3. Current smokers }\end{array}$} \\
\hline Drinking & \multicolumn{6}{|c|}{$\begin{array}{l}\text { 1. No drinking } \\
\text { 2. Less than once a month } \\
\text { 3. } 2-4 \text { times a month } \\
\text { 4. } 2 \text {-3 times a week } \\
\text { 5. More than } 4 \text { times a week }\end{array}$} \\
\hline Scholarship & \multicolumn{6}{|c|}{$\begin{array}{l}\text { 1. No education } \\
\text { 2. Elementary school } \\
\text { 3. Middle school } \\
\text { 4. High school } \\
\text { 5. University }\end{array}$} \\
\hline Work time & \multicolumn{6}{|c|}{$\begin{array}{l}\text { 1. Work duration } \\
\text { : average }\left(\frac{\text { months/year }}{\text { years }}\right) \\
\text { 2. Total work duration }(\text { y }\end{array}$} \\
\hline
\end{tabular}




\section{Carpal tunnel syndrome protocols (A)}

1. Clinical signs

\begin{tabular}{|l|l|l|}
\hline & Right & \multicolumn{1}{|c|}{ Left } \\
\hline 1. Do you have numbness or loss of sensation in your hand? & Yes/No & Yes/No \\
\hline 2. Do you have pain in your hand or wrist and is it more severe at night? & Yes/No & Yes/No \\
\hline 3. Do the symptoms get better after shaking your hands? & Yes/No & Yes/No \\
\hline 4. Do the symptoms worsen after doing a task with repeated wrist movement? & Yes/No & Yes/No \\
\hline 5. Do you have any difficulty with grasping and using small objects such as keys or pens? & Yes/No & Yes/No \\
\hline 6. Do you have pain in extending your neck and upper extremity? & Yes/No & Yes/No \\
\hline
\end{tabular}

\section{Physical examinations}

1) Neurological test

\begin{tabular}{|l|l|l|}
\hline & Right & Left \\
\hline 1. Motor Examination: APB Weakness & $+/-$ & $+1-$ \\
\hline APB atrophy & $+/-$ & $+1-$ \\
\hline
\end{tabular}

2) Provocation test

\begin{tabular}{|l|c|c|}
\hline & Right & Left \\
\hline Phalen's test $(1 \mathrm{~min})$ & $+/-$ & $+/-$ \\
\hline Durkan's carpal compression test & $+/-$ & $+/-$ \\
\hline Tinel's sign & $+/-$ & $+/-$ \\
\hline
\end{tabular}




\section{Carpal tunnel syndrome protocols (B)}

\section{Electrodiagnostic findings}

1) CMAP

\begin{tabular}{|c|c|c|c|c|}
\hline Left side & Distance $(\mathrm{cm})$ & Distal latency (ms) & Amplitude (mV) & Forearm velocity $(\mathrm{m} / \mathrm{s})$ \\
\hline $\begin{array}{l}\text { Median nerve } \\
\text { (APB recording) }\end{array}$ & 8 & & & \\
\hline $\begin{array}{l}\text { Ulnar nerve } \\
\text { (ADQ recording) }\end{array}$ & 8 & & & \\
\hline Right side & Distance $(\mathrm{cm})$ & Distal latency (ms) & Amplitude (mV) & Forearm velocity $(\mathrm{m} / \mathrm{s})$ \\
\hline $\begin{array}{l}\text { Median nerve } \\
\text { (APB recording) }\end{array}$ & 8 & & & \\
\hline $\begin{array}{l}\text { Ulnar nerve } \\
\text { (ADQ recording) }\end{array}$ & 8 & & & \\
\hline
\end{tabular}

2) $S N A P_{-} 1$

\begin{tabular}{|c|c|c|c|c|}
\hline Left side & Distance $(\mathrm{cm})$ & Distal latency $(\mathrm{ms})$ & Amplitude $(\mathrm{mV})$ & Forearm velocity $(\mathrm{m} / \mathrm{s})$ \\
\hline $\begin{array}{c}\text { Median nerve } \\
\text { (second finger recording) }\end{array}$ & 14 & & & \\
\hline $\begin{array}{c}\text { Ulnar nerve } \\
\text { (fifth finger recording) }\end{array}$ & 14 & & & \\
\hline
\end{tabular}

\begin{tabular}{|c|c|c|c|c|}
\hline Right side & Distance $(\mathrm{cm})$ & Distal latency $(\mathrm{ms})$ & Amplitude $(\mathrm{mV})$ & Forearm velocity $(\mathrm{m} / \mathrm{s})$ \\
\hline $\begin{array}{c}\text { Median nerve } \\
\text { (second finger recording) }\end{array}$ & 14 & & & \\
\hline $\begin{array}{c}\text { Ulnar nerve } \\
\text { (fifth finger recording) }\end{array}$ & 14 & & & \\
\hline
\end{tabular}

3) SNAP_2

\begin{tabular}{|c|c|c|c|c|}
\hline Left side & Distance $(\mathrm{cm})$ & Distal latency $(\mathrm{ms})$ & Amplitude $(\mathrm{mV})$ & Forearm velocity $(\mathrm{m} / \mathrm{s})$ \\
\hline $\begin{array}{c}\text { Median nerve } \\
\text { (fourth finger recording) }\end{array}$ & 14 & & & \\
\hline $\begin{array}{c}\text { Ulnar nerve } \\
\text { (fourth finger recording) }\end{array}$ & 14 & & & \\
\hline
\end{tabular}

\begin{tabular}{|c|c|c|c|c|}
\hline Right side & Distance $(\mathrm{cm})$ & Distal latency (ms) & Amplitude (mV) & Forearm velocity (m/s) \\
\hline $\begin{array}{c}\text { Median nerve } \\
\text { (fourth finger recording) }\end{array}$ & 14 & & & \\
\hline $\begin{array}{c}\text { Ulnar nerve } \\
\text { (fourth finger recording) }\end{array}$ & 14 & & & \\
\hline
\end{tabular}

4) Conclusion of Electrodiagnosis

Right hand: CTS (+/-)

Left hand: CTS (+/-)

(*Dominant hand: Right/left)

Bland Scale Right ( ) Left ( ) 